\title{
Surgical treatment of clinically early-stage endometrial carcinoma without systematic lymphadenectomy
}

\author{
Artur lício Rocha Bezerra ${ }^{1}$, Thales Paulo Batista ${ }^{1,2^{*}}$, Mário Rino Martins ${ }^{2}$, Vandré Cabral Gomes Carneiro ${ }^{1,2}$ \\ ${ }^{1}$ Faculdade Pernambucana de Saúde, Instituto de Medicina Integral Professor Fernando Figueira (FPS/IMIP), Recife, PE, Brazil \\ ${ }^{2}$ Hospital do Câncer de Pernambuco, Recife, PE, Brazil
}

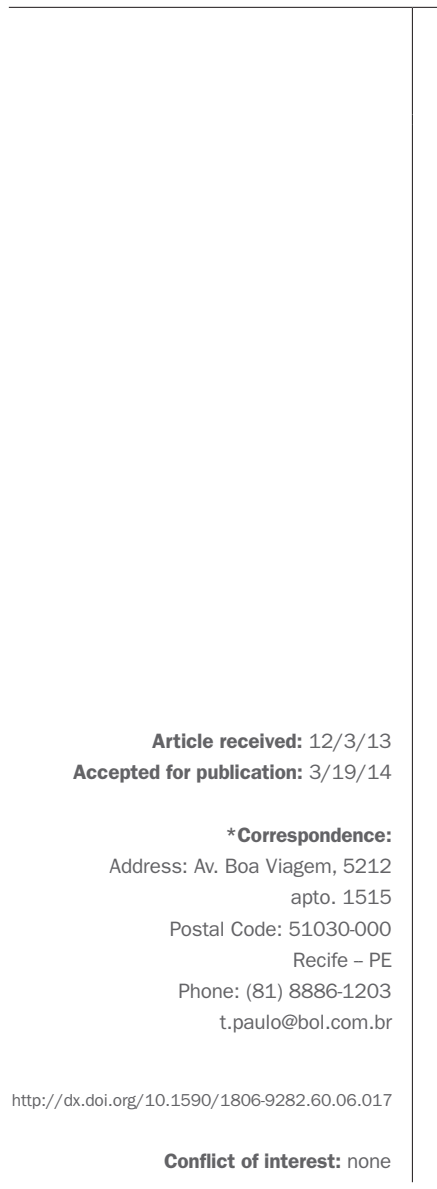

\section{SUMmARY}

Objective: the main aim of this study was to describe the authors' experience with the surgical treatment of endometrial cancer without systematic lymphadenectomy.

Methods: a retrospective cohort study was carried out on a subset of patients suffering of clinically early-stage endometrial carcinoma who underwent hysterectomy and salpingo-oophorectomy without systematic (radical) lymph nodes dissection at our centers from June, 2002, to November, 2011. Descriptive statistics were explored as medians (interquartile range) or frequencies (percentages), as appropriated, and the Kaplan-Meier method was applied for survival estimation.

Results: eighty-three patients who underwent surgical treatment with no lym$\mathrm{ph}$ node dissection $(\mathrm{n}=20 ; 24.1 \%)$ or with only a sampling procedure $(\mathrm{n}=63$; 75.98\%) were selected for analysis. Among these patients, 27 (32.53\%) underwent surgery alone and $56(67.46 \%)$ received some adjuvant treatment. Postoperative complications occurred in five patients (6.02\%). Over a median follow-up of 27.4 months $\left(\mathrm{Q}_{25}=13.7-\mathrm{Q}_{75}=46.5\right), 15(18.07 \%)$ patients suffered from relapses and 11 deaths occurred as result of disease recurrence. Cumulative 1, 2 and 3-year disease-free survivals were $97.32,91.18$ and $78.02 \%$, respectively.

Conclusion: on a case-by-case basis, the surgical treatment of clinically early-stage endometrial carcinoma without systematic lymphadenectomy did not seem to decrease survival outcomes and presented low rates of surgical morbidity in our experience, but was also related to a high rate use of adjuvant therapy.

Keywords: endometrial neoplasms, survival analysis, lymph node dissection.

\section{INTRODUCTION}

Endometrial cancer is the most frequent malignancy of the female genital tract in developed countries and stands as second most common in developing countries, accounting for approximately 319,498 newly diagnosed cases of cancer worldwide. ${ }^{1}$ An estimated 5,900 new cases of endometrial cancer are expected to be diagnosed in $2014 / 2015$ in Brazil, with a cumulative risk estimated in $5,79 / 100,000$ women in this country. ${ }^{2}$ Fortunately, since vaginal bleeding is commonly associated with the presence of disease, the majority of patients with endometrial cancer are diagnosed at an early-stage, resulting in ove- rall favorable prognosis with high cancer-specific survival rates. ${ }^{3,4}$

Although simple hysterectomy plus bilateral salpingo-oophorectomy remains a cornerstone for the management of endometrial cancer, whether patients suffering of this malignancy would benefit from systematic lymph node dissection is a matter of great debate..$^{5-10}$ The pelvic lymph nodes represent the most common site of extra-uterine disease in patients with clinical early-stage disease and thus, pelvic lymph node dissection is incorporated as an integral part of the standard surgical procedures recommen- 
ded to treat early-stage endometrial carcinomas,; ${ }^{3}$ however more conservative surgical approaches without lymphadenectomy might reduce treatment-related morbidity in these settings.

Since evidences from two large randomized European trials reporting that lymphadenectomy had no effect on survival for women with apparent early-stage endometrial cancer, ${ }^{5,6}$ this current study aimed to describe our experience with the management of early-stage endometrial carcinoma in a subset of our patients who underwent surgical treatment without systematic lymphadenectomy.

\section{Methods}

\section{Study design}

A retrospective cohort study was carried out on patients who underwent surgical treatment for early-stage endometrial carcinoma at the Hospital de Cancer de Pernambuco (HCP) and at the Instituto de Medicina Integral (IMIP) from June, 2002, to November, 2011. Using our own database, we included for analysis patients who underwent hysterectomy and salpingo-oophorectomy without systematic lymph nodes dissection or with only a sampling dissection. We also limited our study to adults $(\geq 18$ years) with complete data in their medical records and excluded patients with $\geq 10$ nodes dissected in the sampling procedure or who had gross and unresectable extra-uterine disease at laparotomy, and those patients with non-epithelial/mixed histology (i.e.: carcinosarcomas). This study protocol was reviewed by our Ethics Research Committee (CAAE: 09894712.9.0000.5201).

\section{Variables, outcomes and analytical approach}

The baseline characteristics were reviewed as some clinical/ pathologic prognostic factors, such as age, histological type and grade, lymph node metastasis, depth of myometrial invasion, cervical involvement, evidence of extra-uterine disease, and pathological FIGO stage. We summarized the descriptive statistics as medians (interquartile range) or frequencies (percentages), as appropriated.

Disease-free survival was explored as a function of time after surgical treatment until the date of disease recurrence or the end of the study. Data on those patients with no recurrence at the time of analysis were 'censored' for survival estimation. Patients were usually followed up with clinical general/pelvic exams, lab tests and imaging exams every 3-6 months in the first two years, every 6-12 months up to 5-year, and annually thereafter. The Statistica Data Analysis Software System, Version 8.0 (Statsoft, Inc., Tulsa, OK, USA) was used to disease-free survival estimation applying the Kaplan-Meier method.

\section{Sample characteristics}

A subset of 104 patients suffering from clinically early-stage endometrial carcinoma was treated surgically without systematic lymphadenectomy at our centers from June, 2002, to November, 2011. All of them had biopsy-proven endometrial carcinoma reported after pre-operative hysteroscopy $(n=67,63.8 \%)$, uterine curettage $(n=29,27.61 \%)$ or other procedures $(n=8,7.61 \%)$. This sample included patients with endometrioid $(n=92,88.46 \%)$, clear cell $(n=$ $8,7.69 \%)$ and other tumors ( $n=4,3.84 \%)$. Most of the patients did not smoke (85.84\%) and lived at the metropolitan area from the capital city of Pernambuco State (68.67\%). Their median age and number of pregnancies were $63\left(\mathrm{Q}_{25}=56\right.$ $\left.-Q_{75}=70\right)$ and $4\left(Q_{25}=2-Q_{75}=5\right)$, respectively. Amongst these eligible patients, 21 were excluded from our final analysis mainly due to nodal counts $\geq 10$ nodes ( $n=12$ ), gross extra-uterine disease $(n=2)$, loss on follow-up $(n=6)$ and carcinosarcoma histology $(\mathrm{n}=1)$.

The same surgical team performed all procedures using standard techniques (i.e.: hysterectomy and bilateral salpingo-oophorectomy) without systematic lymphadenectomy $(\mathrm{n}=24,23.07 \%)$ or with only a sampling procedure alone ( $\mathrm{n}$ $=80,76.92 \%)$. A single dose of cefazolin (2g) was applied as antibiotic prophylaxis and transurethral catheterization used for postoperative bladder drainage, being removed on the first postoperative day. Adjuvant radiotherapy usually included external pelvic radiotherapy (total dose ranging from 45 to $50 \mathrm{~Gy}$; $180 \mathrm{cGy} /$ day) and/or vaginal HDR brachytherapy fractioned in 4 daily doses (total dose of $15 \mathrm{~Gy}$ ). This treatment was offered based on the pathological FIGO staging and evidence of high-intermediate risk factors. When applied, chemoradiation included concurrent cisplatin-based chemoteraphy $\left(40 \mathrm{mg} / \mathrm{m}^{2}\right)$. Radiation, platinum or taxane-based chemotherapy, and best support care were offered after disease recurrence, as appropriated.

\section{Results}

Our analysis involved 83 patients who underwent surgical treatment with only a sampling procedure $(n=63 ; 75.98 \%)$ or no lymph node dissection ( $n=20 ; 24.1 \%)$. Five patients suffered from postoperative complications (6.02\%), such as 
wound infection $(\mathrm{n}=1)$ and wound dehiscence $(\mathrm{n}=4)$. Among all patients, $56(67.46 \%)$ received some adjuvant treatment, including radiotherapy $(\mathrm{n}=44,53.01 \%)$, chemotherapy $(\mathrm{n}=$ $3,3.61 \%)$ or chemoradiation ( $n=9,10.84 \%)$. The usage rate of adjuvant therapy was 61.9 and $85 \%$ for the sampling and no lymph node dissection groups, respectively. The post-operative pathological exam involved 270 pelvic lymph nodes dissected (median $=3 ; \mathrm{Q}_{25}=1-\mathrm{Q}_{75}=5$ ) from patients who underwent sampling lymph node dissection. Most of them had no metastatic nodes ( $\mathrm{n}=58 ; 92.06 \%)$. Pelvic washing was collected from 75 (90.36\%) patients and none had positive free-cancer cells. Baseline characteristics regarding some clinical and pathological prognostic factors are summarized in Table 1.

At a median follow-up of 27.4 months $\left(\mathrm{Q}_{25}=13.7\right.$ $\left.\mathrm{Q}_{75}=46.5\right), 15$ (18.07\%) patients suffered from disease recurrence. These relapses were recorded as pelvic $(\mathrm{n}=1)$, peritoneal/retro-peritoneal $(n=4)$ vaginal $(n=2)$, distant metastasis to lung $(n=1)$ and bone $(n=1)$, mixed pelvic and retroperitoneal $(n=1)$, and others/not reported $(n=$ 5). Eleven deaths occurred as a result of disease recurrence. Three patients were alive with disease at the time of this analysis, receiving palliative chemotherapy $(n=2)$ or best support care $(\mathrm{n}=1)$. One patient presented vaginal recurrence and received salvage radiotherapy. Overall, our cumulative 1, 2 and 3-year disease-free survivals were 97.32, 91.18 and $78.02 \%$, respectively (Figure 1 ).

\section{Discussion}

Lymph node dissection is performed by skeletonizing vessels and removing lymph node baring fat tissue, whereas a comprehensive systematic lymphadenectomy usually includes the pelvic and para-aortic nodes. Nevertheless, although lymph node dissection is important to nodal staging of patients with endometrial cancer, its therapeutic value for patients with early-stage disease has been questioned. ${ }^{5,6}$ Thus, following the publication of two large randomized European trials suggesting no survival benefit for routine pelvic lymphadenectomy in endometrial cancer ${ }^{5,6}$ we considered important to present our experience with the surgical management of clinically early-stage endometrial without radical lymphadenectomy using our data from Northeast Brazil.

The choice of treatment without systematic lymphadenectomy was made on a case-by-case basis, taking into account clinical/pathologic features, surgical findings

\section{TABLE 1 Baseline characteristics}

Prognostic factors

n (\%)

Age (years)

$\leq 50$

$51-70$

$9(10.8)$

$51-70$

$59(71.1)$

$>70$

$15(18.1)$

\begin{tabular}{l|l}
\hline Histological type & \\
\hline $\begin{array}{l}\text { Endometrioid } \\
\text { Others }\end{array}$ & $74(89.1)$ \\
\hline Histological grade & \\
\hline G1 ${ }^{1}$ & $55(66.8)$ \\
G2/3 & $28(33.7)$ \\
\hline Myometrial invasion & \\
\hline$<50 \%$ & $45(54.3)$ \\
$\geq 50 \%$ & $38(45.8)$ \\
\hline Cervical involvement & \\
\hline Present & $24(28.9)$ \\
Absent & $59(71.1)$ \\
\hline Lymph node metastasis & \\
\hline Present & $5(6)$ \\
Absent & $78(94)$ \\
\hline Extra-uterine disease & \\
\hline Present & $5(6)$ \\
Absent & $78(94)$ \\
\hline FIGO Stage (pathological) & \\
\hline I & $56(67.5)$ \\
II & $18(21.7)$ \\
III & $9(10.8)$ \\
\hline G1:wal &
\end{tabular}

${ }^{1} \mathrm{G} 1$ : well differentiated.

${ }^{2} \mathrm{G} 2$ : moderately differentiated; G3: poorly or undifferentiated.

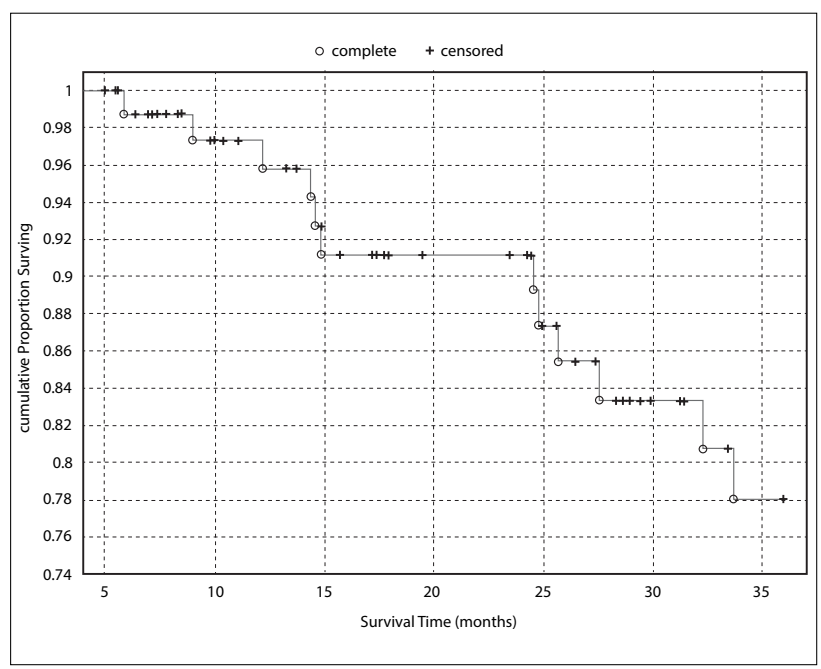

FIGURE 1 Kaplan-Meier disease-free survival. The correspondent 1, 2 and 3-year disease-free survival were 97.32, 91.18 and $78.02 \%$, respectively. 
and patient's characteristics. However, while a radical lymphadenectomy was not performed, the majority of our patients underwent some pelvic lymph node dissection as a sampling procedure in order to improve their nodal staging. In our experience, replacing the systematic lymphadenectomy with a sampling procedure, or no procedure at all, did not impair disease-free survival and also presented low rates of surgical morbidity. Interestingly, albeit similar rates of lymph node metastasis (if nodes harvested), most of our patients $(67.46 \%)$ received some adjuvant treatment compared to the report by Benedetti Panici et al. ${ }^{6}$ and the Astec trial ${ }^{5}$ - about 33\% in both European trials. Similar results were also previously described by Chan et al., ${ }^{11}$ who explored the Surveillance, Epidemiology and End Results (SEER) program conducted by the United States National Cancer Institute from 1988 to 2001, including a population database of 39,396 women with endometrioid corpus cancer who underwent hysterectomy and bilateral salpingo-oophorectomy with or without lymph node resection. According to these authors, women who did not undergo a systematic lymphadenectomy had a significantly increased use of adjuvant radiotherapy, with a usage rate of adjuvant radiotherapy two times higher $(32.8 \% \mathrm{vs}$. $16.4 \%, \mathrm{p}<0.001$ ) - as we also observed comparing our sample to the report by Benedetti Panici et al. ${ }^{6}$ and the Astec trial. ${ }^{5}$ In our experience, the increased use of adjuvant treatments was probably related to the inaccuracies of our preoperative staging and the lack of some standardized prognostic information from the pathological exams (i.e.: lymphovascular invasion) in many of the first years of the period analyzed.

Even though the report by Benedetti Panici et al..$^{6}$ and the Astec trial ${ }^{5}$ have both suggested that lymphadenectomy had no effect on survival for women with apparent early-stage endometrial cancer, some of their limitations are open to criticism as the inclusion of low-risk patients, and the lack of systematic para-aortic lymphadenectomy or lack of standardization of postoperative treatment. ${ }^{7,8}$ In view of these limitations, Todo et al. ${ }^{9}$ compared two cohorts of patients receiving either pelvic lymphadenectomy or combined pelvic and para-aortic lymphadenectomy for endometrial cancer. Applying multivariate analysis, these authors observed that pelvic and para-aortic lymphadenectomy reduced the risk of death compared with pelvic lymphadenectomy alone in patients with intermediate or high risk of recurrence $(0.44,0.30-0.64$; $\mathrm{p}<0.0001)$, suggesting that combined pelvic and para-aor- tic lymphadenectomy should be recommended as treatment for these patients, whereas the pelvic lymphadenectomy alone might be an insufficient surgical procedure for endometrial cancer in patients at risk of lymph node metastasis. ${ }^{9}$ Accordingly, pelvic and para-aortic lymphadenectomy currently have been our preferred approach for patients with intermediate or high risk of recurrence, while conservative surgical approaches with no lymph node dissection or with a sampling dissection alone have been applied in order to reduce treatment-related morbidity only for low-risk patients and old or very obese patients. Unfortunately, laparoscopic approach to endometrial cancer ${ }^{12}$ has not been easily available for our patients from the public health system at present.

Considering the available evidences supporting the surgical treatment of endometrial cancer without lymphadenectomy for low-risk patients, ${ }^{5,6,9,11}$ the identification of patients at low-risk of recurrence before surgery is a cornerstone for the management of this malignancy. ${ }^{13-17} \mathrm{Ne}-$ vertheless, how accurately these patients may be identified preoperatively remains unclear. ${ }^{13}$ Exploring this important issue, Kang et al. ${ }^{14}$ developed a low-risk criteria for lymph node metastasis based on serum CA-125 levels and magnetic resonance imaging data (i.e.: depth of myometrial invasion, lymph node enlargement, and extension beyond uterine corpus) that can be obtained before surgery. According to these authors, this preoperative risk prediction model resulted in the accurate identification of a low-risk group for lymph node metastasis among patients with endometrial cancer $(A U C=0.89)$, with a false negative rate lower than $2 \%$. However, in light of others findings, an accurate evaluation of tumor diameter ${ }^{15}$ and lymphovascular space involvement, ${ }^{16,17}$ both pre or intra-operatively, should also be incorporated as a tool to predict lymph node metastasis and to guide operations with or without radical lymphadenectomy. Whether a selective approach based on predictive models using serum CA-125 and magnetic resonance imaging as criteria or based on intra-operative assessment of pathological prognostic factors is more cost-effective than routine lymphadenectomy in patients with endometrial cancer, especially for developing countries, requires further and careful evaluation. ${ }^{18}$

Finally, it is important to highlight that most of the overall cancer recurrences occur early in the firsts 2-3 years after treatment, which justifies the use of disease-free survival as a primary end-point, especially because the 3-year disease-free survival is an excellent predictor of later overall survival. Further, more than a third of deaths are 
usually not related to endometrial cancer itself, 4,5 probably due to a combination of increased life expectancy and an epidemic of obesity that predisposes to this disease, ${ }^{3}$ which strongly suggest that disease-free survival can be used as a better primary end-point in such studies. In theses settings, we expect to have detected almost all recurrences at the time of this analysis. Additionally, by using a data from Northeast Brazil, this descriptive study made it possible to estimate how reproducible conclusions from European trials can be when applied to heterogeneous populations in Brazil.

\section{Conclusion}

On a case-by-case basis, the surgical treatment of clinically early-stage endometrial carcinoma without systematic lymphadenectomy did not seem to decrease survival outcomes and presented low rates of surgical morbidity in our experience. However, this conservative approach was also related to high rate use of adjuvant therapy.

\section{Resumo}

Tratamento cirúrgico do câncer de endométrio em estágio clínico precoce sem linfadenectomia radical.

Objetivo: descrever a experiência dos autores com o tratamento cirúrgico do câncer de endométrio em estádio precoce sem linfadenectomia radical.

Métodos: realizou-se estudo de coorte retrospectivo envolvendo um subgrupo de pacientes com câncer de endométrio em estágio clínico precoce tratadas com histerectomia e salpingo-ooforectomia sem linfadenectomia radical, em dois centros pernambucanos, de junho de 2002 a novembro de 2011. As variáveis foram descritas como mediana (intervalo interquartílico) ou frequências (percentuais), utilizando-se o método de Kaplan-Meier para a estimativa das taxas de sobrevivência.

Resultados: oitenta e três pacientes submetidas a tratamento cirúrgico sem dissecção linfonodal ( $\mathrm{n}=20,24,1 \%$ ) ou com dissecção apenas por amostragem $(n=63 ; 75,98 \%)$ foram selecionadas para análise. Entre essas pacientes, 27 (32,53\%) foram tratadas somente com cirurgia e $56(67,46 \%)$ receberam tratamento adjuvante. Cinco pacientes apresentaram complicações pós-operatórias (6,02\%). Durante o acompanhamento mediano de 27,4 meses $\left(Q_{25}=13,7-Q_{75}=46,5\right)$, 15 (18,07\%) pacientes apresentaram recorrência, dentre as quais 11 faleceram em decorrência da recidiva neoplásica. Observou-se sobrevivência cumulativa proporcional livre de doença em um, dois e três anos de 97,32, 91,18 e 78,02\%, respectivamente.

Conclusão: em um contexto de indicação caso-a-caso, o tratamento cirúrgico do câncer de endométrio em estádio precoce sem linfadenectomia radical parece não ter prejudicado a sobrevivência e apresentou baixas taxas de morbidade cirúrgica em nossa experiência, mas também foi acompanhado de elevada utilização de terapia adjuvante.

Palavras-chave: neoplasias do endométrio, análise de sobrevida, excisão de linfonodo.

\section{References}

1. Ferlay J, Soerjomataram I, Ervik M, Dikshit R, Eser S, Mathers C, et al. GLOBOCAN 2012 v1.0: Cancer Incidence and Mortality Worldwide: IARC CancerBase $\mathrm{N}^{\text {o. }} 11$ Lyon: International Agency for Research on Cancer; 2013. [cited 2014 mar 10]. Available from:globocan.iarc.fr.

2. Brazilian Ministry of Health. Estimation 2014: Cancer incidence in Brazil. Rio de Janeiro: National Cancer Institute (INCA); 2014. [cited 2014 mar 10]. Available from:http://www.inca.gov.br/estimativa/2014/.

3. Benedet JL, Bender H, Jones H $3^{\text {rd }}$, Ngan HY, Pecorelli S. FIGO staging classifications and clinical practice guidelines in the management of gynecologic cancers. FIGO Committee on Gynecologic Oncology. Int J Gynaecol Obstet.2000;70(2):209-62.

4. Creutzberg CL, van Putten WL, Koper PC, Lybeert ML, Jobsen JJ, WárlámRodenhuis CC, et al. Surgery and postoperative radiotherapy versus surgery alone for patients with stage-1 endometrial carcinoma: multicentre randomised trial. PORTEC Study Group. Post Operative Radiation Therapy in Endometrial Carcinoma. Lancet. 2000;355(9213):1404-11.

5. ASTEC study group, Kitchener H, Swart AM, Qian Q, Amos C, Parmar MK Efficacy of systematic pelvic lymphadenectomy in endometrial cancer (MRC ASTEC trial): a randomised study. Lancet. 2009;373(9658):125-36.

6. Benedetti Panici P, Basile S, Maneschi F, Alberto Lissoni A, Signorelli M, Scambia G, et al. Systematic pelvic lymphadenectomy $v$ s. no lymphadenectomy in early-stage endometrial carcinoma: randomized clinical trial. J Natl Cancer Inst. 2008;100(23):1707-16.

7. Uccella S, Podratz KC, Aletti GD, Mariani A. Re: Systematic pelvic lymphadenectomy $v$ s. no lymphadenectomy in early-stage endometrial carcinoma: randomized clinical trial. J Natl Cancer Inst. 2009;101(12):8978; author reply 898-9

8. Creasman WT, Mutch DE, Herzog TJ. ASTEC lymphadenectomy and radiation therapy studies: are conclusions valid? Gynecol Oncol. 2010;116(3):293-4.

9. Todo Y, Kato H, Kaneuchi M, Watari H, Takeda M, Sakuragi N. Survival effect of para-aortic lymphadenectomy in endometrial cancer (SEPAL study): a retrospective cohort analysis. Lancet. 2010;375(9721):1165-72.

10. Dowdy SC, Mariani A. Lymphadenectomy in endometrial cancer: when, not if. Lancet. 2010;375(9721):1138-40.

11. Chan JK, Wu H, Cheung MK, Shin JY, Osann K, Kapp DS. The outcomes of 27,063 women with unstaged endometrioid uterine cancer. Gynecol Oncol. 2007;106(2):282-8

12. Barbosa CP, Moscovitz T, Martins NV, Souza AMB, Soubhia IT, Aldrighi APS. [Laparascopic approach to endometrial cancer]. Rev Bras Ginecol Obstet. 1999;21(1):41-5.

13. Kang S, Lee JM, Lee JK, Kim JW, Cho CH, Kim SM, et al. How low is low enough? Evaluation of various risk-assessment models for lymph node metastasis in endometrial cancer: a Korean multicenter study. J Gynecol Oncol. 2012;23(4):251-6.

14. Kang S, Kang WD, Chung HH, Jeong DH, Seo SS, Lee JM, et al. Preoperative identification of a low-risk group for lymph node metastasis in endometrial cancer: a Korean gynecologic oncology group study. J Clin Oncol. 2012;30(12):1329-34. 
15. Alhilli MM, Podratz KC, Dowdy SC, Bakkum-Gamez JN, Weaver AL, McGree $\mathrm{ME}$, et al. Risk-scoring system for the individualized prediction of lymphatic dissemination in patients with endometrioid endometrial cancer. Gynecol Oncol. 2013;13(1):103-8.

16. Vaizoglu F, Yuce K, Salman MC, Basaran D, Calis P, Ozgul N, et al. Lymphovascular space involvement is the sole independent predictor of lymph node metastasis in clinical early stage endometrial cancer. Arch Gynecol Obstet. 2013;288(6):1391-7.
17. Zhang C, Wang C, Feng W. Clinicopathological risk factors for pelvic lymph node metastasis in clinical early-stage endometrioid endometrial adenocarcinoma. Int J Gynecol Cancer. 2012;22(8):1373-7.

18. Clements AE, Tierney BJ, Cohn DE, Straughn JM Jr. Is selective lymphadenectomy more cost-effective than routine lymphadenectomy in patients with endometrial cancer? Gynecol Oncol. 2013;128(2):166-70. 